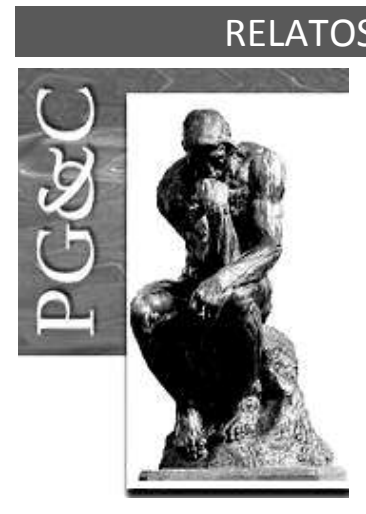

\title{
POLÍTICAS DE GESTÃO DE ACERVOS: POSSÍVEIS FONTES DE INFORMAÇÃO PARA TOMADA DE DECISÃO NOS MUSEUS
}

\author{
Raquel França Garcia Augustin \\ Mestre em Ciência da Informação pela Universidade Federal de Minas \\ Gerais, Brasil. Professora da Universidade Federal de Pelotas, Brasil. \\ E-mail: rfgaugustin@gmail.com \\ Cátia Rodrigues Barbosa \\ Doutora em Muséologie Des Sciences Naturelles Et Humaines pela Ecole \\ Du Muséum National D'histoire Naturelle de Paris, França. Professora da \\ Universidade Federal de Minas Gerais, Brasil. \\ E-mail: catiarb@eci.ufmg.br
}

\begin{abstract}
Resumo
A presente pesquisa visa analisar as políticas de gestão de acervo disponibilizadas via web pelo Museu de Astronomia e Ciências Afins, Fundação Joaquim Nabuco, Casa de Oswaldo Cruz e Museu Paraense Emilio Goeldi, no sentido de analisar as políticas de gestão de acervos como possíveis fontes de informação com diretrizes para a tomada de decisão relacionada à preservação do patrimônio musealizado. Apresentam-se conceitos e temáticas como fontes de informação, tomada de decisão e políticas de gestão de acervos, a fim de analisá-los e correlacioná-los. Conclui-se que as políticas apresentam distintos níveis de aprofundamento nos aspectos dos processos analisados, disseminando informações principalmente quanto a etapas processuais e critérios vinculados às tomadas de decisão. Por fim, observa-se que a temática da preservação é evidente na composição do texto das políticas de gestão de acervos e na valorização dos processos componentes como aspectos condicionantes da musealização dos bens culturais.
\end{abstract}

Palavras-chave: Gestão da Informação. Políticas de Gestão de Acervos. Preservação. Museu.

\section{COLLECTIONS MANAGEMENT POLICIES: POSSIBLE SOURCES OF INFORMATION FOR DECISION-MAKING IN MUSEUMS}

\begin{abstract}
The present research aims to analyze the collection management policies made available through the web by the Museum of Astronomy and Related Sciences, Joaquim Nabuco Foundation, Casa de Oswaldo Cruz and Museu Paraense Emilio Goeldi, to understand how this documents present the information as sources of information for decision-making about preservation in museums. Concepts and themes such as information sources, decision-making and collection management policies are presented in order to analyze and correlate them. It is concluded that the policies presents different approaches on collections management processes, disseminating information about decision-making criteria and procedural steps of collection management. Finally, it is observed that the preservation theme is evident in the composition of the text of the collection management policies and in the value of the processes that are components of the musealization of cultural assets.
\end{abstract}

Keywords: Information management. Collection Management Policies. Preservation. Museum. 


\section{INTRODUÇÃO}

Os museus são instituições comprometidas com a preservação e a comunicação dos bens culturais considerados patrimônio. Para atingir suas atividades-fim a instituição se utiliza de atividades-meio como a aquisição, a documentação e a conservação das coleções sob sua guarda. Essas atividades compõem a gestão das coleções e apresentam desafios vinculados à preservação do suporte material e à logística de operações, como padrões de conservação inadequados, backlogs de documentação, organização espacial ineficiente nas reservas técnicas, lacunas na padronização dos procedimentos básicos e falta de clareza nos critérios de aquisição e alienação de bens.

O documento que planeja e organiza a gestão de acervos nos museus é chamado de política de gestão de acervos e engloba de forma geral temas como a aquisição, a documentação, a conservação, o empréstimo e a alienação dos bens culturais musealizados, dentre outros, objetivando apresentar diretrizes de ação para a equipe do museu. 0 documento diferencia-se do plano museológico, configurando-se como um anexo desse. Apresenta rotinas e orientações, não diagnósticos, metas, planos e cronogramas, como o plano museológico.

O presente artigo, produto da dissertação de mestrado intitulada "Políticas de gestão de acervos, instrumentos auxiliares na tomada de decisão: análises de documentos disponibilizados por museus brasileiros na web" defendida pela autora em março de 2017, almeja analisar as políticas de gestão de acervos como possíveis fontes de informação com diretrizes para a tomada de decisão relacionada à preservação do patrimônio musealizado. Para estabelecer tal relação são apresentados temas e conceitos como fontes de informação, tomadas de decisão nos museus e políticas de gestão de acervos.

A análise realizada nessa pesquisa contribui com a compreensão desse documento enquanto fonte de informação para os setores da organização. Ela visa agregar informações sobre a gestão da informação na instituição museológica, assunto que apresenta poucos estudos específicos em português. Essa pesquisa segue a produção de estudos, apresentando interfaces entre a Ciência da Informação, a Museologia e a Conservação-Restauração, áreas que contribuem para a preservação da informação presente nas instituições museológicas. A respeito da tipologia de documentos a ser analisada (políticas de gestão de acervos de museus), existem poucas publicações disponíveis em português, havendo uma concentração maior de estudos em língua inglesa.

\section{POLÍTICAS DE GESTÃO DE ACERVOS}

Os documentos que registram as políticas de gestão de acervos constituem-se como fontes de informação e registros de dados sobre as práticas institucionais produzidas pelo museu. São documentos que auxiliam no entendimento das operações institucionais e que se constituem como material de consulta no que tange ao posicionamento do museu diante de demandas e situações que exijam tomadas de decisões relacionadas aos acervos, tornando-se aparato de embasamento e respaldo para justificar tais decisões.

O âmbito da gestão de acervos é conceituado por Padilha (2014) como a salvaguarda das coleções, o cuidado com o bem-estar físico e o conteúdo do acervo, a sua segurança a longo prazo, o acesso público ao seu conteúdo e a descrição das atividades particulares realizadas pelo processo administrativo do museu. Já Paaskoski, Ekosaari e Jantunen (2014) resumem o sistema de gestão de acervos como um modo de operação que agrega a incorporação, a supervisão, o cuidado e o uso dos acervos museológicos.

Percebe-se, por meio das definições, que a gestão de acervos compreende vários processos e, consequentemente, atividades. A norma Spectrum, padrão para gestão de

Perspectivas em Gestão \& Conhecimento, João Pessoa, v. 8, n. 1, p. 134-154, jan./abr. 2018. 
coleções de museus do Reino Unido, enumera tais processos ao detalhar os procedimentos a serem desenvolvidos e sua respectiva documentação de apoio para uma gestão de coleções mais eficaz (COLLECTIONS TRUST, 2014). Os procedimentos apresentados concentram-se em quatro grandes áreas, escolhidas de acordo com as temáticas das políticas de orientação sugeridas pelo sistema de acreditação de museus do Reino Unido: desenvolvimento das coleções (pré-entrada, entrada do objeto, aquisição, desincorporação e alienação), documentação (controle de inventário, controle de movimentação e localização, catalogação, seguros e indenização, avaliação, auditoria, gestão de direitos, saída do objeto e documentação retrospectiva), acesso às coleções (entrada e saída por empréstimo e uso das coleções) e preservação e conservação das coleções (transporte, avaliação técnica do estado de conservação, conservação e preservação das coleções, gestão de riscos e perdas e danos). A norma Spectrum se tornou referência internacional sobre os fluxos de trabalho relacionados à gestão de acervos museológicos, sendo utilizada por mais de 23.000 instituições ao longo de 40 países (COLLECTIONS TRUST, 2014). Atualmente, seu uso é amplamente incentivado pelo comitê do Icom - CIDOC -, relacionado à documentação em museus.

Após análise das definições propostas por esses autores e por outros presentes nos artigos "Aproximações entre a gestão da informação e do conhecimento e a gestão de acervos no museu" (AUGUSTIN, 2015) e "Políticas de gestão de acervos: um estudo de caso" (AUGUSTIN, BARBOSA, 2016, no prelo) considera-se a gestão de acervos como um sistema de gerenciamento integrado de processos de aquisição, documentação, conservação, empréstimo e alienação de bens culturais musealizados com o intuito de preservá-los e fornecer condições de disseminá-los.

De acordo com a pesquisa realizada, o conteúdo das políticas de gestão de acervo compreende, assim, no mínimo, de forma generalizada, os temas aquisição, documentação, conservação, empréstimo e alienação de bens culturais. No entanto esses temas não são restritivos, apresentam o conteúdo mínimo esperado nesses documentos. Segundo Ladkin (2004, p.28) as políticas podem ser muito mais abrangentes e englobar diversos tópicos, detalhando os temas mínimos esperados e acrescentando outros, como missão e objetivo do museu, código de ética, inscrição, aquisição e incorporação, título de propriedade válido, proveniência e obrigação de diligência, materiais sensíveis e protegidos, avaliação e autenticação, abatimento e cedência, devolução e restituição, catalogação, numeração e identificação, inventário, empréstimos, relatório sobre o estado de conservação e glossário/padrões, documentação, preservação do acervo, armazenamento do acervo, manuseio e movimentação do acervo, fotografia, prevenção de acidentes, seguro, acessibilidade do acervo, segurança, exposições, controle do ambiente adequado, monitoramento do acervo em exposição, materiais de exposição apropriados, embalagem e transporte, investigação, recolha de campo, ambiente interno, eruditos e investigadores visitantes, análise destrutiva, coleta pessoal e utilização pessoal do acervo, conservação preventiva e conservação.

Em decorrência de sua abrangência, a autora define a política de gestão de acervos como o documento mais importante do acervo do museu, pois, por meio dele, as tomadas de decisão cotidianas podem ser fundamentadas. Nesse sentido, Simmons (2004, p. 47-48) reitera que,

em virtude das políticas de gestão de acervos auxiliarem a equipe do museu a cumprir suas incumbências, elas devem também: definir as áreas de responsabilidade da equipe, delegar a autoridade de tomada de decisão aos comitês ou aos indivíduos apropriados, identificar quem tem autoridade para fazer exceções à política (se necessário) e orientar a equipe a manter

Perspectivas em Gestão \& Conhecimento, João Pessoa, v. 8, n. 1, p. 134-154, jan./abr. 2018. 
registros completos em relação às decisões e às atividades vinculadas às coleções (Tradução nossa).

A diretriz nas políticas de gestão de acervos referente ao estímulo ao registro das orientações concernentes às atividades rotineiras e suas respectivas tomadas de decisão mencionada por Simmons contribui para o enriquecimento da memória organizacional por incitar a documentação dos critérios e elementos que influenciaram a tomada de decisão na instituição. Somados a tais registros, as políticas de gestão de acervos explicitadas sob a forma de documentos internos permitem a conferência da eficácia dos procedimentos que a elas se relacionam, tornando-se, à luz da gestão da informação, fontes de informação nos museus visto que são documentos produzidos pela organização e constituem instrumentos físicos de registro de dados a respeito do museu e de sua prática organizacional, contribuindo com a compreensão dos processos executados no museu, fornecendo, inclusive, orientações para o estabelecimento de protocolos de procedimentos a serem implantados para aprimorar e padronizar tais processos (BUCK; GILMORE, 2007).

\section{FONTES DE INFOMAÇÃO}

A gestão da informação ocorre de forma processual, abarcando procedimentos que conectam o reconhecimento das necessidades de informação do usuário com as fontes de informação que podem conter tais dados, seu tratamento, a distribuição e o uso, apoiando o processo de tomada de decisão. Davenport $(1998$, p.173) conceitua a gestão da informação como o "conjunto estruturado de atividades que incluem o modo como as empresas obtêm, distribuem e usam a informação e o conhecimento". Choo (2003) especifica mais o conceito ao defender que tais atividades têm por fim a adaptação e as mudanças dos ambientes interno e externo, vinculando-se ao aprendizado organizacional. Tarapanoff (2006) acrescenta que a gestão da informação visa identificar e potencializar recursos informacionais de uma organização ou empresa e sua capacidade de informação, através do uso do ciclo da informação nas organizações. A autora explica que o ciclo informacional começa quando se inicia a necessidade de obter informações sobre algo, contemplando as "fontes e o acesso, a seleção e aquisição, registro, representação, recuperação, análise e disseminação da informação, que, quando usada, aumenta o conhecimento individual e coletivo" (TARAPANOFF, 2006, p.23). Nesse sentido, evidencia-se o papel primordial da identificação das fontes de informação para a gestão da informação nas organizações.

As fontes de informação podem ser compreendidas como "tudo o que gera ou veicula informação" (RODRIGUES, BLATTMANN, 2014, p.10). Segundo Pacheco e Valentim (2010), a análise das fontes de informação pelos usuários leva em consideração aspectos de relevância, precisão e adequação à demanda organizacional que gera tal necessidade de informação. Os autores argumentam que a avaliação da relevância é influenciada pela confiabilidade da fonte, de seu formato, do estado, da localização e da percepção do usuário. Quanto à categorização, podem ser divididas de acordo com quatro quesitos: através da proximidade com os dados originais/autor, através da natureza de sua procedência, através de sua estrutura e através de sua localização perante a organização.

A proximidade com o autor define a fonte de informação como primária, secundária ou terciária. As fontes primárias possuem a interferência direta do autor no conteúdo. As secundárias organizam as fontes primárias, apresentando as informações selecionadas e organizadas com alguma finalidade. Dessa forma, conferem um tratamento diferenciado aos dados, organizando-os, como manuais, enciclopédias e monografias. Já as terciárias são as mais distantes do autor, aquelas que possibilitam e orientam a busca pelas fontes primárias e

Perspectivas em Gestão \& Conhecimento, João Pessoa, v. 8, n. 1, p. 134-154, jan./abr. 2018. 
secundárias, como as bibliografias e os diretórios (PACHECO; VALENTIM, 2010; CARVALHO, 2001).

A natureza de sua procedência define as fontes de informação como pessoais ou impessoais. As fontes pessoais são pessoas que comunicam informações de maneira direta ao indivíduo, como fornecedores, colegas de trabalho e outros profissionais; já as impessoais são as fontes que transmitem informações a uma gama maior de pessoas, como publicações, palestras, databases etc (CHOO, 1994; PACHECO; VALENTIM, 2010).

A estrutura de uma fonte de informação a classifica como formal ou informal. As fontes formais são aquelas que possuem um suporte físico, presentes em documentos; já as informais não apresentam suporte físico, podem ser adquiridas oralmente ou por meio da internet, como correios eletrônicos, chats de discussão etc (CARVALHO, 2001).

A localização perante a organização determina se as fontes são internas ou externas. As fontes internas compreendem as informações produzidas na organização ou por pessoas que trabalhem na organização, como relatórios, memorandos, políticas, manuais e colegas de trabalho. As externas são compostas por informações produzidas fora da organização ou por pessoas não vinculadas profissionalmente à organização, como publicações de órgãos internacionais, reportagens de revistas ou jornais, especialistas na área, bibliotecas, patentes, autoridades locais etc.

Kaye (1995) defende que a maioria de fontes usadas por gestores de organizações são as pessoais. Pacheco e Valentim (2010) acrescentam que a obtenção de informações através de outra pessoa apresenta possibilidades além da informação em si, como aconselhamentos, incentivos, apoios e auxílio na existência de opções a escolher. Mas isso não desmerece as informações impessoais, as quais também podem esclarecer as dúvidas do indivíduo e auxiliálo a resolver a demanda organizacional sem depender do contato com outro indivíduo. Esse afinal é um dos objetivos das políticas de gestão de acervos: constituírem-se enquanto fontes de informação ativas na instituição, com uso efetivo pelos funcionários para apoio à tomada de decisão. Como fontes primárias, impessoais, formais e internas, as políticas se constituem documentos confiáveis aos indivíduos, apresentando as diretrizes referentes aos processos de aquisição, documentação, conservação, empréstimo e alienação dos acervos da instituição. Dessa forma, são relevantes à elaboração de protocolos de procedimentos referentes a esses processos e à execução de tais processos, devendo ser geridas para que sejam disseminadas aos indivíduos que delas necessitem.

\section{TOMADA DE DECISÃO REFERENTE À GESTÃO DE ACERVOS NOS MUSEUS}

Para o êxito da gestão da informação, é preciso que a organização compreenda a informação como um recurso estratégico em um ambiente cuja cultura e comportamento informacionais estejam consolidados. Choo (2003, p. 275) aponta a existência de quatro tipos de modelos de tomada de decisão nas organizações: o modelo racional, o processual, o político e o anárquico. O modelo racional é definido como aquele em que "a tomada de decisões é um ato orientado para objetivos e guiado por problemas, e o comportamento de escolha, um comportamento regulado por normas e rotinas, de modo que a organização possa agir de uma maneira procedimental e intencionalmente racional". O modelo processual apresenta fases e ciclos que estruturam as atividades decisórias complexas e dinâmicas. Já no modelo político, "a política é o mecanismo de decisão quando diferentes jogadores ocupam diferentes posições e exercem graus diferentes de influência, de modo que as decisões resultam menos de uma escolha racional do que dos altos e baixos da política". E no modelo anárquico, há uma referência ao chamado modelo da lata de lixo "no qual as organizações são semelhantes a latas de lixo onde os problemas e soluções são atirados pelos participantes, e as

Perspectivas em Gestão \& Conhecimento, João Pessoa, v. 8, n. 1, p. 134-154, jan./abr. 2018. 
decisões resultam do encontro de correntes independentes de problemas, soluções, participantes e situações de escolha".

De acordo com uma análise das características dos modelos e do possível uso das políticas de gestão de acervos como fontes de informação referentes à preservação dos acervos museológicos, faz-se plausível depreender que o modelo de tomada de decisão vinculado a esse uso seja o modelo racional. O modelo é caracterizado por Choo (2003) da seguinte forma:

a) A incerteza técnica envolvida no processo é baixa, pois se preza pela racionalidade local, ou seja, cada unidade é responsável por resolver os problemas de seu campo de especialização, acarretando numa decisão bem estruturada, guiada por regras e rotinas, envolvendo participantes e interesses bem definidos.

b) Em virtude de as decisões serem guiadas por regras, rotinas e programas de desempenho, o processo de tomada de decisão é simplificado, reduzindo a necessidade de busca e de escolha.

c) As decisões são orientadas para objetivos sequenciais, os quais são claros e conservam baixa ambiguidade ou conflito, assim a decisão tende a tomar a forma da solução de um problema, sendo guiada por um conjunto claro de objetivos e preferências.

d) O resultado atingido possui caráter satisfatório, não sendo necessariamente o melhor resultado possível, mas uma alternativa que atenda aos critérios estabelecidos.

e) $O$ aprendizado organizacional associado ao processo decisório decorre da adaptação de objetivos, de regras de atenção e de regras de busca, ou seja,

[...] os objetivos são adaptados com base no desempenho e na experiência passada, e na comparação desses resultados com os de outras organizações equivalentes. As regras de atenção são adaptadas à medida que a organização aprende a observar certos aspectos do ambiente e, assim, a dar mais atenção a alguns critérios e a ignorar outros. As regras de busca são adaptadas quando a organização não consegue encontrar uma solução viável usando uma certa estratégia ou, ao contrário, quando descobre uma alternativa interessante buscando de uma certa maneira. (CHOO, 2003, p. 281-282).

Depois de apontar as diversas formas de fontes de informação, descrever o modelo de tomada de decisão racional e caracterizar as políticas de gestão de acervos como recursos informacionais institucionais tocantes às orientações e às rotinas relativas às etapas de gestão de acervos reitera-se que é possível inferir que as decisões tomadas em relação a essas etapas com consulta às políticas podem se configurar como tomadas de decisão decorrentes do modelo racional, já que ele prevê um comportamento decisório baseado em rotinas e em documentos orientadores, realizado de acordo com a especialidade de cada funcionário, com grau de incerteza baixo que atinja a um objetivo por vez de forma satisfatória.

Pensar no processo de tomada de decisão relacionado aos processos de gestão de acervos, implica analisar as situações-problema intrínsecas a esses processos e conceber uma relação dos fatores que podem contribuir para o desenvolvimento dessa tomada de decisão.

A tomada de decisão está presente em qualquer processo que envolva escolhas, critérios, prioridades e seleções. Apresenta-se, por exemplo, na determinação do que deve ou não ser adquirido pelo museu; no estabelecimento de quais informações devem ser registradas a respeito dos objetos e de quais critérios embasam esse registro, ou seja, como ele deve ser realizado; na determinação das medidas de conservação que devem ser tomadas para a preservação dos itens; na determinação de quais são os itens mais valiosos ao acervo; no estabelecimento de parâmetros que indiquem a necessidade de restauração dos itens; na

Perspectivas em Gestão \& Conhecimento, João Pessoa, v. 8, n. 1, p. 134-154, jan./abr. 2018. 
indicação de como os objetos devem ser embalados e transportados no caso de empréstimos etc.

A política de gestão de acervos não determina nenhuma dessas decisões, pois ela tem por função orientar o responsável por essas decisões a respeito do posicionamento institucional atribuído a esses casos, do comportamento esperado pela organização. Mas, no processo de tomada de decisão referente à gestão de acervos, as políticas devem ser consideradas em adição a diversos outros fatores, como a infraestrutura espacial e tecnológica disponível, a relação custo-benefício das opções avaliadas, o tempo que cada alternativa levará para ser realizada, a quantidade de integrantes da equipe e suas respectivas capacitações, os riscos aos bens culturais implícitos a algumas opções de escolha e a missão institucional (FIGURA 1).

Figura 1 - Aspectos a serem considerados na tomada de decisão referente à gestão do acervo

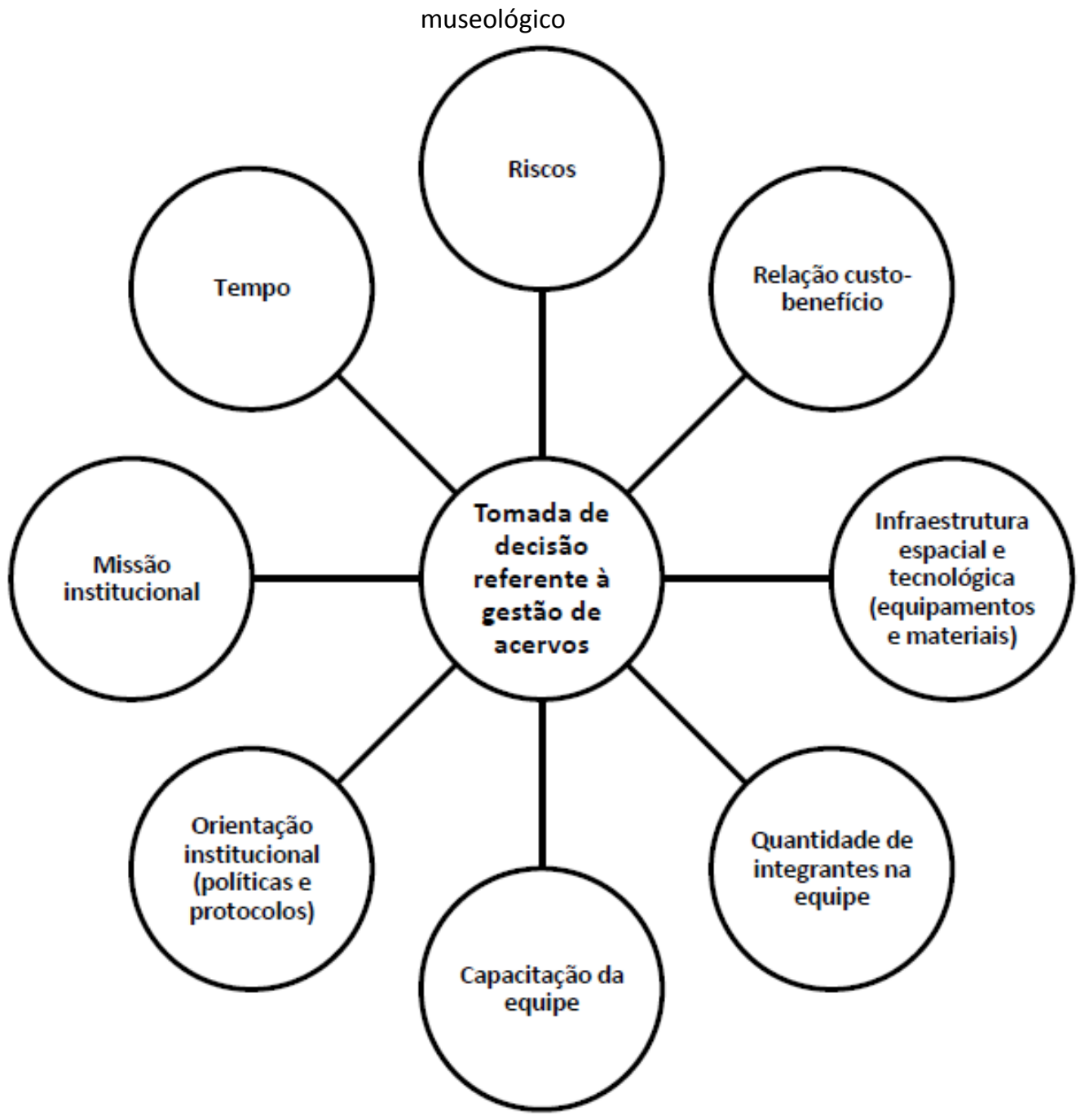

Fonte: Augustin (2017, p. 32)

A tomada de decisão relativa à gestão de acervos envolve questões procedimentais, protocolares e técnicas, mas também envolve questões ideológicas referentes principalmente ao recorte do acervo e à missão da instituição.

Por vezes, a carência de documentação e/ou o estado de conservação de um bem musealizado são condicionantes para sua incorporação em atividades de disseminação da

Perspectivas em Gestão \& Conhecimento, João Pessoa, v. 8, n. 1, p. 134-154, jan./abr. 2018. 
informação, como mostras, exposições, publicações ou empréstimos. Por meio das políticas de gestão de acervos, as instituições divulgam seus parâmetros de gestão de acervos para o público e para a própria equipe, justificando suas escolhas ao apresentar os critérios que as guiaram. Dessa forma, os documentos conferem transparência e seriedade ao processo decisório, respaldando a tomada de decisão.

As políticas enquanto guias de orientação colaboram para uma tomada de decisão mais eficiente e racional, mas também podem promover "a rigidez das rotinas decisórias e dos valores que orientam a decisão" caso sejam formuladas de forma a não orientar uma decisão, mas sim a impor uma decisão. Os documentos não devem ser taxativos em seu conteúdo, ao contrário, devem apresentar orientações que direcionem o curso de ação das situações. Assim, infere-se que o reconhecimento das fontes de informação e de sua relevância para a organização se faz essencial para o uso da informação de forma estratégica, visto que cada área, setor e indivíduo da organização apresenta necessidades de informações distintas, pertinentes à sua função na instituição. No decorrer do processo de tomada de decisão, a busca por informação é motivada pelo surgimento de problemas que precisam ser solucionados. Essa busca é influenciada pelos hábitos e pelas preferências individuais, pelos valores da organização refletidos na institucionalização de regras e rotinas voltadas a escolhas congruentes com os objetivos organizacionais e pela situação de escolha (CHOO, 2003). O comportamento de busca da informação "parece respeitar uma hierarquia de fontes de informação, que é ordenada pela proximidade em relação a um problema ou a seus sintomas, e pelas características das fontes, como sua acessibilidade ou credibilidade" (CHOO, 2003, p.310). Dessa forma, a gestão da informação se justifica enquanto processo organizacional nos museus e em outras organizações, pois é através dela que a informação será representada e então recuperada num sistema, constituindo uma memória organizacional ativa da instituição. Essa memória é uma base que está vinculada ao sistema de gestão da informação responsável pelos documentos e pelas fontes ali gerenciados, como documentos técnicos, registros de soluções encontradas, políticas institucionais e documentos resultantes da externalização do conhecimento tácito dos indivíduos. Nos museus, tal sistema é associado ao sistema de documentação museológica, o qual, quando criado como sistema de gestão integrada, apresenta documentos referentes a questões institucionais, curatoriais e técnicas vinculadas ao processo de musealização e, consequentemente, à gestão de acervos, como políticas e protocolos de gestão, dossiês de conservação ou restauração, relatórios de estado de conservação, fichas de catalogação, inventários, mapeamentos de localização de obras, especificações de empréstimo etc. Isso evidencia que uma das maiores contribuições da memória organizacional é a preservação da memória técnica, gerencial e de negócios da organização e a constituição de um conjunto de fontes que contribuem para o aprendizado organizacional (YAGUI, 2003). Com isso, ela contribui para evitar a repetição de erros, a duplicação de esforços, o retrabalho ao armazenar soluções, informações e conhecimentos pertinentes já adquiridos e desenvolvidos pela organização e a perda do conhecimento corporativo com a saída de indivíduos importantes para a instituição (FERREIRA; FELL, 2014).

No que tange às políticas de gestão de acervos, a memória organizacional colabora com seu desenvolvimento ao reunir informações referentes a critérios de aquisição, alienação, empréstimo, conservação e documentação das peças componentes do acervo utilizados anteriormente, assim como a casos específicos que geraram problemas ou benefícios para a organização. Concomitantemente, a memória enquanto sistema de preservação e reutilização da informação garante um uso crítico das políticas que foram atualizadas ou substituídas. Assim, a gestão da informação administra seu ativo desde a percepção da necessidade da informação até a sua produção, disseminação e reutilização. Nos museus, o sistema de gestão da informação colabora com a musealização do acervo ao fornecer e preservar fontes de 
informação cruciais para a realização dos processos de gestão e utilização das coleções, como, por exemplo, as políticas de gestão de acervos.

\section{PROCEDIMENTOS METODOLÓGICOS}

Essa pesquisa realizou análises das políticas de gestão de acervos, contemplando os documentos disponibilizados na web de quatro instituições museológicas brasileiras: O Museu do Homem do Nordeste (Muhne) (gerido pela Fundação Joaquim Nabuco), o Museu de Astronomia e Ciências Afins (Mast), o Museu Paraense Emílio Goeldi (Mpeg) e a Casa de Oswaldo Cruz (COC). Os estudos de caso realizados contemplam uma análise crítica do conteúdo de tais documentos como possíveis fontes de informação relacionadas à tomada de decisão, no que tange à preservação dos acervos musealizados.

As políticas foram levantadas por meio do buscador Google e do acesso ao site de cada uma das instituições denominada museu, ecomuseu ou pinacoteca cadastradas no "Guia de museus brasileiro" (INSTITUTO BRASILEIRO DE MUSEUS, 2011). Para uma instituição ser considerada um museu ela não precisa se intitular como tal, visto que o Icom (2007) e a legislação nacional (Brasil, lei 11.904, 2009) definem a instituição museal como um espaço a serviço da sociedade que preserva, pesquisa e comunica o patrimônio cultural da humanidade e seu entorno visando a educação, estudo e contemplação dos bens. Mas para fins de otimização da pesquisa optou-se pela visita aos sites somente das instituições denominadas museu, ecomuseu ou pinacoteca, excluindo o levantamento das páginas web de parques, jardins botânicos, zoológicos, fundações culturais, bibliotecas, centros culturais, memoriais, institutos culturais e galerias, os quais também se enquadram na definição mencionada.

Os documentos foram recuperados nos portais online das instituições e selecionados se apresentassem todos os tópicos integrantes da gestão de acervos em sua estrutura (aquisição, alienação, empréstimo, documentação e conservação de acervos). Outros documentos foram recuperados, mas não foram utilizados por não contemplarem o conteúdo pretendido em sua completude. Esses documentos eram políticas de aquisição e descarte e políticas de empréstimo, em sua maioria.

\section{RESULTADOS}

A análise crítica do conteúdo foi permeada por um viés comparativo entre os documentos, visando demonstrar possibilidades de abordagem distintas e escolhas de conteúdo. A análise não visa comparar os documentos julgando se os posicionamentos são mais ou menos adequados. Sua intenção é demonstrar os diferentes tipos de disseminação da informação veiculados nas fontes de informação que podem ser associadas às tomadas de decisão.

Os documentos, de forma geral, se estruturam em diversos tópicos, conforme apresentado na definição presente nesse artigo. As informações referentes à tomada de decisão aplicada a cada um desses tópicos por vezes aparece explicitamente, na forma de critérios a serem considerados e etapas a serem seguidas; por vezes, aparece implicitamente nas diretrizes presentes no texto.

Inicialmente verificou-se a menção pelas políticas a códigos de ética, regras deontológicas e a legislação nacional, averiguando-se que sua citação, apesar de ratificar o conhecimento dos dizeres presentes no conteúdo dos códigos e leis oferecendo um maior índice de confiabilidade à fonte de informação (política de gestão de acervos) e gerando maior segurança e respaldo na tomada de decisão, ocorreu apenas em dois documentos: a política de aquisição e descarte do Mast e de preservação e gestão da COC.

Perspectivas em Gestão \& Conhecimento, João Pessoa, v. 8, n. 1, p. 134-154, jan./abr. 2018. 
Em seguida verificou-se quais informações presentes ali poderiam ser auxiliares à tomada de decisão referente aos processos de aquisição e alienação dos bens culturais. A política de aquisição e descarte do Mast e os documentos da Fundaj, da COC e do Mpeg exibem a existência de critérios para aquisição e para alienação de peças, informando ao público as justificativas de suas escolhas e concedendo um embasamento para a equipe responsável por tais ações, a qual também é destacada na delegação de responsabilidades presente nos documentos. O critério de seleção presente em todos os documentos é a conformidade com o interesse da instituição (Quadro 1). Em seguida, os critérios mais presentes são: o estado de conservação das obras, a continuidade ou complementaridade das coleções existentes e a viabilidade de sua preservação, ou seja, se as instituições possuem infraestrutura adequada, recursos humanos e condições financeiras para arcar com sua conservação. Dentre os critérios apresentados, destaca-se a viabilidade de preservação das obras, visto que ele transmite o compromisso ético e a responsabilidade dos museus com a conservação do patrimônio cultural e sua transmissão para as gerações futuras, assim como uma interface com as medidas de conservação do acervo.

Quadro 1 - Critérios de seleção e modos de aquisição presentes nos documentos analisados

\begin{tabular}{|c|c|c|}
\hline Instituição & Critérios de seleção & Modo de aquisição \\
\hline Mast & $\begin{array}{l}\text { Estado de conservação; importância histórica e científica; } \\
\text { custos envolvidos com transferência, conservação, } \\
\text { armazenamento e manutenção; importância política do } \\
\text { acervo; raridade; dimensões; demandas referentes à sua } \\
\text { preservação, incluindo recursos humanos, materiais e } \\
\text { estruturais; ameaça de perda, destruição ou venda; } \\
\text { consequências de sua remoção do contexto original (para a } \\
\text { comunidade, o meio ambiente e a própria obra); existência } \\
\text { de uma instituição regional que também reivindica a guarda } \\
\text { do acervo, e que garante poder mantê-lo em boas condições } \\
\text { de guarda; possibilidade de aprofundar temas de estudo ou } \\
\text { dar continuidade a coleções já existentes. }\end{array}$ & Não são mencionados \\
\hline Fundaj & $\begin{array}{l}\text { Consonância com seu perfil e objetivos; meios financeiros, } \\
\text { orçamentários, e condições espaciais e ambientais que } \\
\text { garantam a conservação e a preservação do acervo. Não } \\
\text { aceita doações com restrições específicas. }\end{array}$ & $\begin{array}{l}\text { Compra, doação e } \\
\text { transferência }\end{array}$ \\
\hline $\mathrm{COC}$ & $\begin{array}{l}\text { Estado de conservação, objetos significativos para a história e } \\
\text { a memória institucional e elucidativos para desenvolvimento } \\
\text { de estudos da História das Ciências e da Saúde no Brasil; } \\
\text { recursos financeiros da instituição; capacidade de espaço } \\
\text { para armazenamento; disponibilidade de pessoal para } \\
\text { tratamento e proposição de condições ideais de preservação; } \\
\text { autoria; complementaridade; conteúdo; pertinência; } \\
\text { procedência; raridade e viabilidade. }\end{array}$ & $\begin{array}{l}\text { Comodato, compra, } \\
\text { depósito legal, doação, } \\
\text { guarda temporária, } \\
\text { permuta, recolha e } \\
\text { transferência }\end{array}$ \\
\hline Mpeg & $\begin{array}{l}\text { Estado de conservação, conformidade com os interesses da } \\
\text { coleção. }\end{array}$ & $\begin{array}{l}\text { Coleta de campo, } \\
\text { doações, intercâmbio } \\
\text { com outras instituições } \\
\text { e compras }\end{array}$ \\
\hline
\end{tabular}

Fonte: Augustin (2017, p. 62)

Em conformidade com o critério de viabilidade da preservação supracitado, estabelecendo uma relação com os processos de documentação e conservação, a política de aquisição e descarte do Mast acrescenta que os objetos de grandes dimensões devem ter seu processo de desmontagem registrado de forma integral e providencial para facilitar sua 
posterior remontagem e que, caso não possam ser remontados em um prazo curto, só devem ser adquiridos se extremamente raros.

Reitera-se também que embora apresente como critério a continuidade de suas coleções, a política do Mast informa que pode receber itens alheios a suas áreas de interesse se esses receberem um parecer favorável da comissão responsável e apresentarem-se em estado de risco. Ressalta-se, com isso, uma exceção a um critério pré-estabelecido e a relevância da disseminação, nas políticas, das características das coleções das instituições, do tipo de objeto de interesse para o acervo. A divulgação das áreas de interesse fornece respaldo para a equipe estabelecer parâmetros e prioridades de busca de acervo novo, assim como para recusar ofertas que não são do interesse institucional, facilitando o processo de tomada de decisão e garantindo a manutenção do foco das coleções de acordo com a missão da instituição e sua área de trabalho.

Em relação à delegação de responsabilidades concernente à aquisição e ao descarte, as políticas do Mast, da Fundaj e da COC citam a existência de uma comissão permanente de aquisição e descarte de acervo e de departamentos ou coordenações responsáveis pelo seu tratamento técnico. Já a política do Mpeg destaca as atribuições e as responsabilidades de cada funcionário de acordo com seu cargo: curador, assistente de curadoria ou técnico em acervo. Destaca-se que a política da Fundaj apresenta procedimentos com alto grau de detalhamento quanto às etapas a serem seguidas nos processos de aquisição e alienação, fato que ressalta seu caráter orientador para a equipe quanto à tomada de decisão cotidiana.

Quanto aos critérios e meios de alienação do acervo (Quadro 2), conclui-se que todas as instituições apresentam como um dos critérios o estado de conservação dos itens, levando em consideração também o desinteresse da instituição em sua manutenção no acervo em virtude de sua temática, a quantidade de peças de mesma representação e a falta de informações sobre os itens. Destaca-se que os meios mais recorrentes de alienação são as doações e descartes.

Os processos de aquisição e alienação de itens associam-se aos de conservação e documentação em virtude da necessidade de registro das tomadas de decisão, da elaboração de pareceres técnicos favoráveis ou desfavoráveis a determinadas escolhas e das primeiras medidas de identificação dos itens. Com isso, as instituições determinam a elaboração de determinados documentos para dar prosseguimento às etapas de aquisição e alienação (QUADRO 3).

Percebe-se que a maior parte das políticas solicita um dossiê informativo com a relevância da aquisição para a instituição e um registro dos motivos que levaram ao descarte da peça, no caso de alienação. As políticas adicionam a importância de manutenção de tais registros, mesmo após a alienação das peças. Concomitantemente a isso, o documento demonstra a importância da documentação museológica para a gestão de acervos ao compor, de forma técnica e administrativa, tais processos e viabilizar o acesso às informações pertinentes a suas etapas e tomadas de decisão.

Em relação à utilização das políticas de gestão de acervos como possíveis fontes de informação para a tomada de decisão referente ao processo de documentação, pode-se inferir que tal orientação ocorre mais no nível procedimental, indicando rotinas de tratamento técnico do acervo, como a menção a fichas de catalogação, registro fotográfico, inventários, controle de movimentação etc.

Já em relação à tomada de decisão referente à conservação, pode-se inferir que ela perpassa as instâncias da conservação preventiva, da conservação curativa e da restauração. Correntemente a conservação engloba a reflexão a respeito de soluções para problemas referentes à preservação da integridade dos bens culturais, determinando os limites de risco aceitáveis para cada situação (GRUPO ESPANHOL DO IIC, 2012). Em geral, a tomada de decisão está vinculada ao estabelecimento de condições mais próximas às ideais por meio da 
infraestrutura e dos recursos de que o museu dispõe, ou seja, a tomada de decisão do processo de conservação estabelece as conexões entre a condição ideal de conservação do bem e a condição possível de acordo com os meios acessíveis pela instituição.

Quadro 2 - Critérios e modos de alienação apresentados nos documentos estudados

\begin{tabular}{|c|c|c|}
\hline Instituição & Critérios de alienação & Modo de alienação \\
\hline Mast & $\begin{array}{l}\text { - Presença de deteriorações que possam } \\
\text { representar perigo para os profissionais do } \\
\text { museu, visitantes, coleções ou instalações; } \\
\text { - Encontrarem-se em estado fragmentado, de } \\
\text { forma que não possam ser identificados; } \\
\text { - Não existirem informações vinculadas à } \\
\text { procedência dos objetos; } \\
\text { - O museu não possuir condições de conservação } \\
\text { ou seu custo for elevado para a instituição; } \\
\text { - Não serem da área de interesse da instituição. }\end{array}$ & $\begin{array}{l}\text { - Doação; } \\
\text { - Transferência; } \\
\text { - Troca; } \\
\text { - Repatriação; } \\
\text { - Destruição. }\end{array}$ \\
\hline Fundaj & $\begin{array}{l}\text { - Deterioração; } \\
\text { - Desinteresse; } \\
\text { - Desaparecimento. }\end{array}$ & $\begin{array}{l}\text { - Deterioração: incineração ou } \\
\text { doação à instituição que trate de } \\
\text { reciclagem de materiais não } \\
\text { orgânicos; } \\
\text { - Desinteresse: transferência à outra } \\
\text { instituição museológica pública ou } \\
\text { oferta em leilão. }\end{array}$ \\
\hline $\mathrm{COC}$ & $\begin{array}{l}\text { - Itens deteriorados que não possam ser } \\
\text { identificados ou restaurados e/ou que } \\
\text { representem perigo para profissionais, visitantes } \\
\text { ou instalações; } \\
\text { - Itens excessivamente repetidos no acervo; } \\
\text { - Bens fora da área de interesse do museu. }\end{array}$ & $\begin{array}{l}\text { - Baixa temporária (item que sofreu } \\
\text { roubo, furto ou desaparecimento); } \\
\text { - Descarte (item deteriorado); } \\
\text { - Permuta; } \\
\text { - Doação. }\end{array}$ \\
\hline Mpeg & $\begin{array}{l}\text { - Bem em estado avançado de deterioração, não } \\
\text { servindo mais aos fins científicos; } \\
\text { - Número de exemplares ou peças representados } \\
\text { na Coleção; } \\
\text { - Importância das peças; } \\
\text { - Relevância do destino a ser dado ao material; } \\
\text { - Outros. }\end{array}$ & $\begin{array}{l}\text { - Doação; } \\
\text { - Outros. }\end{array}$ \\
\hline
\end{tabular}

Fonte: Augustin (2017, p. 63)

Nota-se que as políticas apontam a importância do controle ambiental nas áreas de guarda e exposição e as condições de armazenamento e acondicionamento dos itens, assim como apresentam parâmetros quanto à restauração dos bens. A política da COC comenta que os profissionais devem seguir o princípio da mínima intervenção, da reversibilidade e da identificação das intervenções, devem, ainda, respeitar as características artísticas, históricas, científicas e técnicas dos objetos, obedecendo a "princípios de procedência e autenticidade, a fim de manter a relação entre os objetos e seus elementos característicos, o que determina sua especificidade e valor como objeto museológico" (CASA DE OSWALDO CRUZ, 2013, p. 16). Já a política do Mast apresenta a restauração como atividade de caráter excepcional que deve eleger a restituição da funcionalidade do objeto ao antepor os tratamentos de estabilização e consolidação do bem cultural aos de caráter estético e salienta o posterior desenvolvimento de critérios de normatização e priorização dos procedimentos de restauração, destacando que eles devem contemplar: 
a) documentação técnica prévia do bem cultural e do seu estado de conservação;

b) documentação técnica dos procedimentos, com vistas ao registro das intervenções e produtos utilizados;

c) recomendações quanto às condições de guarda e de utilização do bem cultural após tratamento;

d) priorização em função do valor intrínseco, estado de conservação, procedimentos de intervenção, domínio da técnica, entre outros. (MUSEU DE ASTRONOMIA E CIÊNCIAS AFINS, 1995, p. 26)

Assim, percebe-se que o conteúdo referente à tomada de decisão voltada à conservação do acervo foi abordado de distintas formas: por meio da indicação dos parâmetros norteadores das propostas de intervenção, por meio das etapas envolvidas e da documentação correlacionada e por meio da indicação do estabelecimento de priorizações e da orientação de desenvolvimento de documentos secundários (protocolos de procedimentos ou normativas).

A menção aos parâmetros evidencia a posição oficial da instituição quanto aos processos de intervenção nos bens culturais sob sua custódia, rememorando os diversos aspectos de interpretação dos bens de acordo com o processo de musealização pelo qual os itens do acervo passaram.

A citação à documentação referente ao processo de restauração enaltece a importância dos registros para a memória organizacional da instituição ao manter armazenadas as tomadas de decisão referentes aos procedimentos, aos materiais, às técnicas e aos resultados nas intervenções de restauração. Corroborando com essa análise, a política da COC afirma que as ações de preservação devem ser monitoradas e registradas com fins de "avaliar a efetividade, eficiência e eficácia das soluções adotadas e fornecer subsídios para o planejamento das ações futuras" (CASA DE OSWALDO CRUZ, 2013, p. 9).

A alusão à determinação de priorizações e seus critérios de reflexão estabelece uma linha clara a ser seguida para a tomada de decisão, cuja menção no documento auxilia o responsável por estas escolhas ao determinar e disseminar os princípios a serem considerados.

Por fim, a citação à elaboração de documentos secundários (protocolos de procedimentos ou normativas), conforme comentado anteriormente, reitera a formalização do documento como um guia de orientação para a formulação de documentos técnicos derivados da mesma temática, protocolos de procedimentos, que apresentam as ações rotineiras desenvolvidas de forma detalhada e sistemática, a fim de padronizar a execução desses procedimentos.

Em relação às informações presentes nas políticas referentes à tomada de decisão vinculada ao processo de empréstimo, são encontrados dados referentes aos documentos técnicos e às etapas processuais de execução da solicitação.

Quanto aos documentos técnicos, a política da Fundaj e a do Mpeg (Coordenações de Zoologia e de Ciências Humanas) destacam esmiuçadamente o conteúdo dos documentos necessários à solicitação de empréstimo para exposições. A saber:

I - Dados da instituição solicitante e do seu representante oficial.

II - Unidade(s) do acervo do Muhne a ser(em) emprestada(s).

III - Título e período da exposição.

IV - Especificação dos suportes a serem utilizados para a exposição da unidade do acervo do Muhne.

$\mathrm{V}$ - Condições ambientais do espaço.

VI - Esquemas de segurança contra incêndio e roubo.

Perspectivas em Gestão \& Conhecimento, João Pessoa, v. 8, n. 1, p. 134-154, jan./abr. 2018. 
VII - Indicação do nome da empresa de transportes especializada, com experiência comprovada de 05 (cinco) anos ininterruptos em transportes de acervos museológicos, contratada para a logística do transporte da(s) unidade(s) do acervo requisitada(s).

VIII - Compromisso de cobertura de seguro da(s) unidade(s) de acervo a ser(em) emprestada(s), condição indispensável para a liberação da(s) mesma(s).

IX - Anexos: cópias autenticadas dos atos constitutivos da instituição solicitante, devidamente registrados, ato de nomeação do representante oficial da instituição solicitante com cópia dos documentos de identificação pessoal (RG e CPF) (será admitida procuração apenas por instrumento público e com poderes especiais e específicos para o empréstimo solicitado), breve histórico da instituição proponente e plantas de arquitetura do projeto da exposição (FUNDAÇÃO JOAQUIM NABUCO, 2010, p. 24).

Esse tipo de detalhamento nas políticas simplifica o processamento das informações pelos setores de documentação ou empréstimo das instituições envolvidas. Quanto aos critérios de viabilidade, o documento da Fundaj salienta que o Muhne tem como condicionante para a liberação das peças um parecer técnico do estado de conservação executado internamente e uma apólice de seguro realizada pela instituição solicitante, assim como a obrigatoriedade do parecer técnico no retorno das peças. Já a política do Mpeg, da Coordenação de Zoologia, apresenta como condicionante o empréstimo apenas com finalidades de pesquisa científica, não sendo permitida nenhuma intervenção no bem cultural sem prévia autorização, sendo necessário o envio de um resumo do trabalho a ser executado. $\mathrm{Na}$ mesma política, a coordenação de Ciências Humanas apresenta como critério condicionante o seguro das coleções ou das peças e sua raridade (as peças solicitadas não podem ser únicas ou raras).

As políticas analisadas expõem critérios condicionantes referentes a aspectos gerais das obras, mas não especificam quais pontos serão considerados no processo de tomada de decisão favorável ou desfavorável ao empréstimo. O Grupo Espanhol do IIC (2012, p.29-30) enumera alguns critérios que geralmente contribuem para uma decisão favorável ou desfavorável ao empréstimo (Quadro 4).

A política de preservação do Mast determina o desenvolvimento de normas técnicas relativas ao processo de empréstimo que abordem pontos, como a normatização e a especificação das embalagens, as condições de manuseio das peças do acervo e o seu estado de conservação. Isso implica a relativização dessas condições de realização do empréstimo como tópicos condicionantes para sua efetivação, conforme mencionado acima, visto que as peças em empréstimo apresentam um alto risco de desenvolvimento ou agravamento de deteriorações em decorrência de técnicas de manuseio inadequadas, embalagens inapropriadas e meios de transporte sem a adaptação necessária.

A política da Fundaj e a do Mpeg (Coordenação de Ciências Humanas) apresentam com detalhes as informações necessárias à documentação de solicitação de empréstimo exigida para a realização dos empréstimos, as características necessárias aos solicitantes do empréstimo das peças, as etapas a serem cumpridas e as condições de realização dos trâmites, incluindo transporte e embalagem do acervo. Dessa forma, facilitam a tramitação e a comunicação com outras instituições, agilizando e facilitando o intercâmbio entre os museus (GRUPO ESPANHOL DO IIC, 2012). 
Quadro 3 - Documentação associada aos processos de aquisição e alienação apresentada nas políticas

\begin{tabular}{|c|c|c|}
\hline Instituição & Documentação associada à aquisição & $\begin{array}{l}\text { Documentação associada à } \\
\text { alienação }\end{array}$ \\
\hline Mast & $\begin{array}{l}\text { Dossiê com o maior número possível de informações } \\
\text { sobre os documentos ou os objetos, relatório com } \\
\text { justificativa da importância do acervo e } \\
\text { documentação complementar. }\end{array}$ & $\begin{array}{l}\text { Relatórios detalhados com a } \\
\text { justificativa para o descarte. }\end{array}$ \\
\hline Fundaj & $\begin{array}{l}\text { Relatório com documento com assinaturas } \\
\text { reconhecidas legalmente, que deverá conter os } \\
\text { dados pessoais completos e as cópias de documentos } \\
\text { autenticadas do proponente, a identificação da obra } \\
\text { ou do acervo que vai ser adquirido e a cópia do } \\
\text { certificado de proveniência, caso não seja o autor, as } \\
\text { condições da aquisição (valor e relevância da } \\
\text { aquisição), a autorização para uso em exposições, } \\
\text { publicações e mídia de divulgação do acervo, no caso } \\
\text { de obra com autoria determinada e ata da reunião da } \\
\text { comissão permanente de política de acervo, da qual } \\
\text { deverão constar o parecer do relator e a deliberação } \\
\text { final. }\end{array}$ & $\begin{array}{l}\text { Descarte por deterioração: } \\
\text { parecer técnico especializado; } \\
\text { Descarte por desinteresse: } \\
\text { relatório com identificação do } \\
\text { item, parecer interno indicando } \\
\text { e justificando as razões do } \\
\text { desinteresse pela unidade do } \\
\text { acervo e parecer de consultor } \\
\text { externo, quando o } \\
\text { conhecimento disponível no } \\
\text { Muhne ou na Fundaj for } \\
\text { insuficiente para assegurar uma } \\
\text { tomada de decisão eficaz. }\end{array}$ \\
\hline Coc & $\begin{array}{l}\text { Dossiê, contendo o maior número possível de } \\
\text { informações sobre o objeto, a saber: condições de } \\
\text { aquisição, contendo valor e relevância histórica e } \\
\text { científica para a instituição; dados pessoais } \\
\text { completos e cópias de documentos do proponente; } \\
\text { identificação do acervo e cópia do certificado de } \\
\text { proveniência, quando for o caso; autorização para o } \\
\text { uso em exposições, a publicação em mídia de } \\
\text { divulgação, no caso de obra com autoria; laudos } \\
\text { técnicos que atestem a capacidade de } \\
\text { armazenamento, conservação e segurança. } \\
\text { Termo de doação, permuta ou de guarda temporária } \\
\text { (quando aplicável). }\end{array}$ & $\begin{array}{l}\text { Dossiê apresentando critérios e } \\
\text { justificativas. }\end{array}$ \\
\hline Mpeg & $\begin{array}{l}\text { As normas gerais não mencionam nenhuma } \\
\text { documentação. Somente a coordenação da coleção } \\
\text { de Zoologia exige que o item esteja perfeitamente } \\
\text { documentado quanto à sua origem, ao local e às } \\
\text { condições de coleta. }\end{array}$ & $\begin{array}{l}\text { Registro do motivo e destino do } \\
\text { item no registro ou no catálogo } \\
\text { da coleção em questão. }\end{array}$ \\
\hline
\end{tabular}

Fonte: Augustin (2017, p. 64)

A inter-relação entre os processos de empréstimo, conservação, documentação é inerente ao sistema de gestão de acervos visto que, nos empréstimos, os outros processos todos se manifestam e devem ser considerados na tomada de decisão. Para que o empréstimo seja realizado, é preciso que sejam efetuadas medidas de conservação, visando à manutenção da integridade dos bens relacionados e à exposição a menor intensidade de riscos de danos possível. A documentação intermedeia todas as atividades, uma vez que fornece os formulários a serem utilizados e registra a memória da operação, possibilitando posteriormente a recuperação da informação vinculada ao empréstimo realizado. Nas políticas de gestão de acervos, é importante que a relação estabelecida entre os processos agregue as considerações às questões pertinentes à documentação e à conservação das obras nas diretrizes presentes no texto. Assim, a precaução com a preservação dos acervos na sua instância informacional e material tende a pautar a orientação à tomada de decisão 
institucional procedimental ou estratégica, elevando a preservação da obra a um dos aspectos prioritários da instituição.

Quadro 4-Critérios condicionantes à tomada de decisão referente ao empréstimo de bens culturais

Critérios para decisão favorável
1. Contribuição para uma exposição
importante.

2. Contribuição com um maior conhecimento sobre o objeto emprestado.

3. Possibilidade do conhecimento de um objeto por seu interesse pedagógico.

4. Possibilidade do contato do objeto com novos públicos.

5. Reunião temporária de peças de um conjunto desmembrado.

6. Exposição e estudo de objetos que não saem dos depósitos.

7. Introdução ou interpretação de outra cultura.

8. Aproveitamento da oportunidade do objeto ser restaurado e atualização de suas condições de conservação.

9. Criação de parcerias para empréstimos entre os museus.

10. Compartilhamento e melhoramento das práticas dos profissionais envolvidos.

\section{Critérios para decisão desfavorável}

1. Restrições legais do proprietário.

2. Valorização simbólica, religiosa ou histórica para a comunidade e a instituição que o custodia, razão pela qual só se empresta em ocasiões excepcionais.

3. Tema da exposição muito limitado ou muito comercial.

4. Presença do objeto na exposição não suficientemente justificada.

5. Fadiga do objeto, causada por suas muitas viagens.

6. Esforço que deverá ser feito para a restauração ou meios de conservação que terão de ser aplicados não proporcionais à qualidade do objeto.

7. Objeto não disponível por causa de sua participação em outra exposição.

8. Objeto solicitado sem a suficiente antecedência.

9. Instituição que faz a petição não reunir os critérios de prevenção relacionados com a segurança, o controle climático, o pessoal especializado etc.

10. Petição proveniente de um país que se encontra em situação política instável.

11. Envolvidos que não possuem idoneidade que garanta as condições do empréstimo.

Fonte: Augustin (2017, p.77) com base em Grupo Espanhol do IIC (2012, p.29-30)

\section{CONSIDERAÇÕES FINAIS}

As políticas de gestão de acervos demonstraram configurar-se como fonte de informação quanto à prática e à cultura organizacionais, sendo úteis na rotina de trabalho e possíveis fontes de informação para a tomada de decisão, classificando-se como ferramenta de trabalho por constituir uma fonte de consulta que reitera continuamente a conexão do processo de musealização com a preservação dos bens culturais.

A presente pesquisa concluiu que as quatro políticas de gestão de acervos analisadas apresentaram em seu conteúdo critérios de aquisição, alienação e empréstimo explicitamente, assim como, apresentaram implicitamente diretrizes de orientação quanto à documentação e conservação dos bens presentes em suas coleções.

A natureza dos critérios de aquisição e alienação é variável, mas sua citação é de extrema relevância para a disseminação de informações sobre os processos e para facilitar a incerteza presente no processo de tomada de decisão referente a incorporações ou desincorporações. Nota-se que as instituições se resguardaram, a apresentar em suas políticas a conformidade com o interesse da instituição como critério, salientando a relação do acervo com a missão da instituição, assim como a avaliação do estado de conservação das peças, a viabilidade de sua preservação e a complementaridade de suas coleções, dentre outros. Assim como os critérios, os meios de aquisição e de alienação foram abordados, desmistificando-se a concepção de que os museus, ao desincorporarem itens, estarão condenando-os à destruição. Salienta-se que as políticas esclarecem meios de alienação distintos do desmantelamento, 
como a doação ou a permuta com outras instituições, a venda em leilões e a doação para uso como material didático, por exemplo.

Além dos critérios de viabilidade dos empréstimos, as políticas apresentaram informações necessárias aos documentos de solicitação, a necessidade de confecção de laudos técnicos ou pareceres e da contratação de seguros para os itens. Não é mencionado, em nenhuma política, os aspectos condicionantes para a aceitação ou a negação das solicitações de empréstimo, os quais se apresentam implícitos no texto. Observou-se uma abordagem mais específica quanto ao desenvolvimento de normativas referentes às condições de transporte, manuseio e embalagem dos bens culturais na política do Mast; e uma mais voltada à parametrização das etapas, às características das instituições, dos documentos enviados e às circunstâncias de efetivação nas políticas da Fundaj e do Mpeg. O que ressalta o caráter livre de elaboração dos documentos, os quais devem se adaptar às necessidades institucionais de forma a serem usados como ferramentas de trabalho e, consequentemente, de preservação.

No que se refere às informações vinculadas à tomada de decisão relacionada à documentação, com a citação quanto ao uso de fichas de catalogação, livros de registro e inventários periódicos em algumas políticas, dissemina-se informações sobre o tratamento técnico documental dos acervos museológicos, introduzindo um detalhamento a respeito do processo de musealização realizado pela instituição, assim como de seu compromisso com a atualização dos registros referentes ao acervo.

As diretrizes de conservação presentes nas políticas destacaram o estado de conservação dos itens como condicionante para aquisição, alienação e empréstimos, assim como deram enfoque para os parâmetros de restauração utilizados. Constatou-se que algumas políticas os enumeram enquanto outras, não. Sua enumeração evidencia a posição oficial da instituição quanto aos processos de intervenção nos bens culturais sob sua custódia, trazendo à tona os diversos aspectos de interpretação de acordo com o processo de musealização, de forma a orientar as decisões intrínsecas ao ato da restauração, no âmbito procedimental e conceitual. A citação do registro da documentação vinculada ao processo de restauração destaca a importância de um sistema integrado de documentação e dos registros para a memória organizacional da instituição ao armazenar as tomadas de decisão referentes aos diversos aspectos das intervenções de restauro.

Os documentos demonstram que a inter-relação dos processos de empréstimo, conservação, documentação está intrinsecamente vinculada ao sistema de gestão de acervos, visto que, nos empréstimos, os outros processos têm papel fundamental. Afinal, as medidas de conservação e de documentação intermediam o processo de empréstimo ao oferecer os subsídios para as tomadas de decisão dele decorrentes.

Em suas partes introdutórias, algumas das políticas indicam que a elaboração do documento teve o intuito de oferecer subsídios à tomada de decisão, a partir de demandas institucionais e dos profissionais envolvidos, que sentiam a necessidade do estabelecimento de diretrizes para nortear suas atividades e torná-las mais consistentes dentro de um perfil institucional. A preservação da memória técnica e gerencial dos museus presente nesses documentos contribui para o aprendizado organizacional e, consequentemente, para a autonomia de agentes decisores.

As tomadas de decisão vinculadas ao processo de gestão de acervo apresentam tanto caráter tático quanto operacional, num aspecto protocolar e procedimental. Da mesma forma que as informações presentes nesses documentos auxiliam tomadas de decisões complexas que devem ponderar riscos e relacionar custo-benefício de determinadas escolhas quanto à preservação dos itens do acervo. Dentre tantos outros aspectos, elas também orientam tomadas de decisão rotineiras pertinentes ao tratamento técnico dos itens.

As diretrizes de orientação e os critérios condicionantes quanto à aquisição, à alienação, ao empréstimo, à documentação e à conservação, na alusão aos métodos de 
registro, aos parâmetros de restauração, à determinação de priorizações e seus critérios de reflexão e à viabilidade de incorporações e desincorporações temporárias ou permanentes direcionam a tomada de decisão, cuja menção no documento auxilia o responsável por estas escolhas ao determinar e disseminar os princípios a serem considerados.

Especialmente em relação à conservação, a tomada de decisão refletida nas políticas de gestão de acervos engloba a reflexão a respeito de soluções para problemas referentes à preservação da plenitude material e conceitual dos bens culturais, estabelecendo parâmetros de risco aceitáveis para cada situação. Assim, o cuidado com a preservação dos acervos na sua instância informacional e material, presente indiretamente em todos os tópicos abordados nas categorias analisadas, tende a pautar a orientação à tomada de decisão institucional, procedimental ou estratégica.

Com isso, identificou-se o modelo de tomada de decisão racional como o mais próximo do aplicável às tomadas de decisão referentes à gestão de acervos que levam em conta a consulta às orientações institucionais presentes nas políticas. Tal constatação baseou-se no estabelecimento de suas características, como o nível baixo de incerteza técnica envolvido, a natureza estruturada das decisões tomadas com base nesse modelo, guiadas por regras e rotinas, a orientação para objetivos sequenciais e o caráter satisfatório das soluções encontradas.

Deste modo, acentua-se a relevância do estudo de normativas nos museus dentro do campo da ciência da informação, de forma a analisar os documentos enquanto fontes documentais, instrumentos de planejamento e comunicação, capazes de oferecer orientações e parâmetros para as atividades e tomadas de decisão. As políticas de gestão de acervos se mostraram habilitadas a oferecer direcionamentos aos processos de tratamento que subsidiam a disseminação da informação nos museus, contribuindo diretamente para a musealização dos bens culturais. Nos textos analisados, é possível perceber uma preocupação com a preservação das coleções visando sua transmissão às gerações atual e futuras da forma mais íntegra possível nos planos material e informacional. De modo que tais textos, além de disseminarem as diretrizes com os leitores, contribuem para a legitimação externa da instituição e o aumento de sua credibilidade, ao transmitir direta e indiretamente em seu conteúdo parte dos princípios norteadores da instituição. Em adição a isso, percebe-se que a disseminação de políticas e de protocolos de gestão de acervos dentro dos museus contribui para a valorização dos profissionais envolvidos nas atividades ali abordadas, pois propicia "condições para a tomada de consciência da importância de cada profissional da instituição, independente da sua função específica, como um agente de preservação" conforme consta nos princípios gerais da Política de Preservação de Acervos do Mast (1995, p.15).

Assim, espera-se que o contato com esta pesquisa incentive as instituições que ainda não desenvolveram suas políticas a fazê-lo, assim como auxilie no desenvolvimento e na apresentação de seu conteúdo informacional, servindo como base de consulta nos momentos de elaboração, aprendizado e reflexão a respeito do tema.

\section{REFERÊNCIAS}

AUGUSTIN, R. F. G. Políticas de gestão de acervos, instrumentos auxiliares na tomada de decisão: análises de documentos disponibilizados por museus brasileiros na web. 2017. 97f. Dissertação (Mestrado) - Programa de Pós-Graduação em Ciência da Informação, UFMG, Belo Horizonte, 2017, Disponível em: http://www.bibliotecadigital.ufmg.br/dspace/handle/1843/BUBD-AP2GWR. Acesso em: 14 set. 2017. 
AUGUSTIN, R. F. G. Aproximações entre a gestão da informação e do conhecimento e a gestão de acervos no museu. In: SEMINÁRIO INTERNACIONAL CIÊNCIA E MUSEOLOGIA: Universo Imaginário, 3., 2015, Belo Horizonte. Anais... Belo Horizonte: MUSAETEC, 2015. p.244-256. Disponível em: https://drive.google.com/file/d/OB1dL4PuL60ChTW1NdWJWWjJxTXc/view. Acesso em: 14 set. 2016.

AUGUSTIN, R. F. G.; BARBOSA, C. R. B. Políticas de gestão de acervos: um estudo de caso. In: ENCUENTRO DE LA ASOCIACIÓN DE EDUCACIÓN Y INVESTIGACIÓN EN CIENCIA DE LA INFORMACIÓN DE IBEROAMÉRICA Y EL CARIBE, 10., 2016, Belo Horizonte. Anais... Belo Horizonte: ECI/UFMG, 2017. Disponível em: https://drive.google.com/uc?export=download\&id=10d BB6HbdqyyssYL24SA e7IKZblvwAX. Acesso em: 06 mar. 2018.

BRASIL. Lei no 11.904, de 14 de janeiro de 2009, Institui o Estatuto de Museus e dá outras providências. Diário Oficial da União de 15/01/2009, P. 1. Disponível em: http://www.planalto.gov.br/ccivil 03/ ato2007-2010/2009/lei/l11904.htm. Acesso em: 22 set. 2015.

BUCK, R. A.; GILMORE, J. A.; AMERICAN ASSOCIATION OF MUSEUMS. Collection conundrums: solving collections management mysteries. Washington, DC: American Association of Museums, 2007.

CARVALHO, K. Disseminação da informação e informação de inteligência organizacional DataGramaZero v. 2, n. 3, 2001. Disponível em: http://www.brapci.ufpr.br/documento.php?dd0=0000001238\&dd1=0cbce. Acesso em: 03 out. 2015.

CASA DE OSWALDO CRUZ. Política de preservação e gestão de acervos culturais das ciências e da saúde. Rio de Janeiro: Fiocruz/COC, 2013. Disponível em: http://www.coc.fiocruz.br/index.php/patrimonio-cultural/politica-de-preservacao-e-gestaode-acervos. Acesso em: 20 dez. 2015.

$\mathrm{CHOO}, \mathrm{C}$. W. Perception and use of information sources in environmental scanning. Library \& Information Science Research, v.16, n.1, p.23-40, 1994. Disponível em: http://choo.fis.utoronto.ca/FIS/ResPub/LISR.html. Acesso em: 10 set. 2015.

CHOO, C. W. A Organização do Conhecimento. São Paulo: SENAC, 2003.

COLLECTIONS TRUST. Spectrum 4.0: o padrão para a gestão de coleções de museus do Reino Unido. São Paulo: Secretaria de Estado de Cultura; Associação de Amigos do Museu do Café, Pinacoteca do Estado de São Paulo, 2014. Disponível em: https://issuu.com/sisemsp/docs/spectrum pt net. Acesso em: 21 set. 2015.

CONSELHO INTERNACIONAL DE MUSEUS. Museum definition. Viena: ICOM, 2007. Disponível em: http://icom.museum/the-vision/museum-definition/. Acesso em: 10 set. 2015.

DAVENPORT, T. Ecologia da informação: por que só a tecnologia não basta para o sucesso na era da informação. São Paulo: Futura, 1998. 
EKOSAARI, M.; JANTUNEN, S.; PAASKOSKI, L. Checklist para uma política de gestão de acervos. Pós: Belo Horizonte, v. 4, n. 8, p. 200 - 229, nov. 2014. Disponível em: https://www.eba.ufmg.br/revistapos/index.php/pos/article/viewFile/216/138. Acesso em: 20 set. 2015.

FERREIRA, G. H. A; FELL, A. F. A. A memória organizacional para a gestão da informação: estudo de caso. In: ENCONTRO NACIONAL DE PESQUISA EM CIENCIA DA INFORMAÇÃO, 15. , 2014, Belo Horizonte, MG. Anais ... Belo Horizonte, MG: UFMG, 2014. p.2084-2101.

FUNDAÇÃO JOAQUIM NABUCO. Política de acervo: manual degerenciamento e uso. Recife, 2010. 53f. Disponível em: http://www.fundaj.gov.br/geral/didoc/politicadeacervoago2010.pdf. Acesso em: 20 dez. 2015.

GRUPO ESPANHOL DO IIC. Conservação preventiva e procedimentos em exposições temporárias. Brodowski, SP: Secretaria de Estado da Cultura de São Paulo, 2012.

INSTITUTO BRASILEIRO DE MUSEUS. Guia dos museus brasileiros. Brasília: MinC/IBRAM, 2011. Disponível em: http://www.museus.gov.br/wp-content/uploads/2011/05/gmb extintos.pdf. Acesso em: 20 set. 2015.

LADKIN, N. Gestão do acervo. In: CONSELHO INTERNACIONAL DE MUSEUS. Como gerir um museu: manual prático. Paris: ICOM-UNESCO, 2004. p. 17-32. Disponível em: http://unesdoc.unesco.org/images/0018/001847/184713por.pdf. Acesso em: 21 abr. 2015.

MUSEU DE ASTRONOMIA E CIÊNCIAS AFINS. Política de preservação de acervos institucionais. Rio de Janeiro: Mast, $1995 . \quad$ Disponível em: http://www.mast.br/pdf/politica de preservacao de acervos institucionais.pdf. Acesso em: 20 dez. 2015.

MUSEU DE ASTRONOMIA E CIÊNCIAS AFINS. Política de aquisição e descarte de acervos. Rio de Janeiro: Mast, 2011.2 Disponível em: www.mast.br/pdf/politica de aquisicao e descarte.pdf. Acesso em: 20 dez. 2015.

MUSEU PARAENSE EMILIO GOELDI. Normas gerais de uso e gerenciamento das coleções científicas. Belém, 1999. Disponível em: http://www.museugoeldi.br/portal/content/documentos-0. Acesso em: 20 dez. 2015.

PACHECO, C. G.; VALENTIM, M. L. P. Informação e conhecimento como alicerces para a gestão estratégica empresarial: um enfoque nos fluxos e fontes de informação. In: VALENTIM, M. (Org.). Gestão, mediação e uso da informação. São Paulo: Cultura Acadêmica, 2010. p. 319341. Disponível em: http://books.scielo.org/id/j4gkh/pdf/valentim-9788579831171-16.pdf. Acesso em: 30 set. 2015.

PADILHA, R. C. Documentação Museológica e gestão de acervo. Florianópolis: FCC, 2014. Disponível em: http://www.fcc.sc.gov.br/patrimoniocultural/arquivosSGC/DOWN 175328Documentacao Mu seologica Gestao Acervo.pdf. Acesso em: 22 set. 2015. 
RODRIGUES, C.; BLATTMANN, U. Gestão da informação e a importância do uso de fontes de informação para geração de conhecimento. Perspectivas em Ciência da Informação, v.19, n.3, p.4-29, jul./set. 2014. Disponível em: http://www.scielo.br/pdf/pci/v19n3/a02v19n3.pdf. Acesso em: 28 set. 2015.

SIMMONS, J. Managing things: crafting a collections policy. Museum News, jan/fev. p. 29-48, 2004. Disponível em: https://www.academia.edu/3623694/Managing things. Acesso em: 19 jun. 2016.

TARAPANOFF, K. Informação, Conhecimento e Inteligência em Corporações: relações e complementaridade. In: Inteligência, informação e conhecimento. Brasília: IBICT, UNESCO, p. 19-36, 2006. Disponível em: http://unesdoc.unesco.org/images/0014/001469/146980por.pdf. Acesso em: 28 set. 2015.

YAGUI, L. M. Memória organizacional: proposta para implantação em uma instituição de ensino superior. Florianópolis: UFSC, 2003. Dissertação (Mestrado em Engenharia de Produção) - Programa de Pós-Graduação em Engenharia de Produção, Universidade Federal de Santa Catarina, Florianópolis, 2003.2 Disponível em: https://repositorio.ufsc.br/bitstream/handle/123456789/85782/224414.pdf?sequence=1\&isAl lowed=y. Acesso em: 28 set. 2015.

Artigo recebido em 29/06/2017 e aceito para publicação em 02/03/2018 